\title{
Clinical profile of 108 cases of oral lichen planus
}

\author{
Pritam K. Mankapure, Jayanti G. Humbe, Mandakini S. Mandale, \\ and Jyoti D. Bhavthankar
}

\begin{abstract}
Department of Oral Pathology and Microbiology, Government Dental College and Hospital, Aurangabad, India
\end{abstract}

(Received August 27, 2015; Accepted November 28, 2015)

\begin{abstract}
Oral lichen planus (OLP) is a $\mathrm{T}$ cellmediated chronic inflammatory disease with a varied clinical presentation. The present clinical study was carried out to clarify the demographic and clinical profile of 108 patients with OLP. The patients were identified based on the diagnostic criteria proposed by van der Meij et al. (2003) modified from the WHO (1978) clinical and histopathologic definition of OLP. Information such as age, gender, clinical presentation and type of OLP, site of involvement, symptoms, extraoral involvement, history of systemic disease, familial occurrence and risk factors like chewing and smoking tobacco, chewing betel quid, alcohol consumption were obtained. Mean age of OLP patients was 45.4 years, and among the identified patients, $\mathbf{7 0 . 4 \%}$ were females. The most frequent clinical type was the reticular form $(\mathbf{8 0 . 6 \%})$. The OLP lesions were symptomatic in $77.8 \%$ of the patients. The buccal mucosa was the most affected site $(\mathbf{8 7 . 9 \%})$ and multiple oral lesions were observed in $41.7 \%$ of the patients. Among the OLP patients, 36.1\% and 4.7\% reported chewing tobacco and smoking tobacco, respectively. Histopathologically, epithelial dysplasia was seen in two cases. The chronic nature of OLP warrants patient education, psychological support and long-term follow up. (J Oral Sci 58, 43-47, 2016)
\end{abstract}

Keywords: demography; diagnosis; lichen planus; oral mucosa; precancerous conditions.

Correspondence to Dr. Pritam K. Mankapure, Room No. 133, Department of Oral Pathology and Microbiology, Government Dental College and Hospital, Dhanvantari Nagar, Aurangabad 431001, Maharashtra, India

E-mail: pritammankapure@gmail.com

doi.org/10.2334/josnusd.58.43

DN/JST.JSTAGE/josnusd/58.43

\section{Introduction}

Oral lichen planus (OLP) was first described clinically by Wilson in 1869 (1). It is a T cell-mediated chronic inflammatory disease that involves a type IV hypersensitivity reaction to antigen variations observed in the mucosal lining and skin (2-4). It affects $1-2 \%$ of the general adult population, and the prevalence in the Indian population is reported to be $2.6 \%(3,5)$. The majority of affected patients present with only oral lesions, which are sometimes referred to as "isolated" OLP $(1,6)$. OLP shows a female predominance and mainly affects adult patients between their fifth and sixth decades of life $(2,3)$. The most frequently involved oral sites are the buccal mucosae, tongue, gingiva, labial mucosa and vermilion of the lower lip. The palate, floor of the mouth and upper lip are rarely affected (7). Extraoral lesions are mainly found on the skin, and especially develop in the flexor regions of the legs and arms and involve the nails. Other mucosal sites include the genitalia, esophagus, larynx, scalp, and conjunctiva (8-10). Possible malignant transformation of OLP is the subject of ongoing and controversial discussion in the literature $(3,11,12)$.

The present clinical study of 108 OLP patients was carried out in attempt to clarify the demographic and clinical profile of OLP patients in the Marathwada region of Maharashtra, India.

\section{Materials and Methods}

The present study was approved by Institutional Ethical Committee (No. 96/14, 2014). Among patients attending the OPD of our institution, 108 with OLP were the subjects of our study. The diagnostic criteria proposed by van der Meij et al. (13) modified from the clinical and histopathologic definition of OLP by the WHO (14) were 
Table 1 Demographic and clinical profile of patients according to OLP subtype

\begin{tabular}{lccc}
\hline Profile & Reticular type & Erosive type & Total \\
\hline Mean age at presentation (years) & $45.57 \pm 14.19$ & $44.90 \pm 11.65$ & $45.44 \pm 13.69$ \\
Gender & 60 & 15 & 75 \\
$\quad$ Female & 27 & 6 & 33 \\
$\quad$ Male & & & \\
Number of sites affected & 51 & 12 & 63 \\
1 & 36 & 9 & 45 \\
$\geq 2$ & & & \\
Oral sites affected & 76 & 19 & 35 \\
$\quad$ Buccal mucosa & 26 & 6 & 18 \\
$\quad$ Gingiva & 14 & 4 & 16 \\
$\quad$ Tongue & 13 & 3 & 2 \\
Labial mucosa & 1 & 1 & 74 \\
$\quad$ Vestibular fornix & & & 34 \\
Symptoms & 54 & 20 & 39 \\
$\quad$ Yes & 33 & 1 & 5 \\
No & & & \\
Tissue abuse habits & 16 & 23 & 5 \\
$\quad$ Smokeless form & 1 & 4 & \\
Smoking & 5 & 11 & \\
Systemic disease & 2 & 3 & \\
Diabetes/Hypertension & & & \\
Extra oral involvement & & & \\
\hline
\end{tabular}

used to identify the cases of OLP. The clinical criteria included mostly bilateral, symmetrical lesions, presence of a reticular pattern i.e. a lace-like network of slightly raised gray white lines, and other subtypes only in the presence of reticular lesions elsewhere in the oral cavity or at the periphery of the lesions. Informed consent was sought from the patients after a complete explanation of the purpose of the study. Non-willing patients and those with lichenoid lesions thought to have arisen as a hypersensitivity reaction to drugs and dental materials such as amalgam, composite and acrylates were excluded from the study. Detailed case histories were recorded. The following clinical data were obtained: patient age, gender, clinical presentation and type of OLP, site of involvement, symptoms, extraoral involvement, history of systemic disease, familial occurrence and risk factors like chewing and smoking tobacco, chewing betel quid, alcohol consumption. In patients with more than one clinical type of lesion, such as reticular and erosive, the most extensive as well as severe form of the disease was used to classify the lesions. OLP patients were reviewed at least six-monthly and lesions were biopsied as indicated by their clinical presentation and previous histological findings.

\section{Results}

Table 1 summarizes the demographic and clinical profile of the OLP patients according to subtypes. Among the
108 patients, 76 (70.4\%) were women and $32(29.6 \%)$ were men. The male to female ratio was 1:2.3, and the mean age of the patients at presentation was $45.44 \pm$ 13.69 years (overall range 17-76 years). Various factors such as stress, spicy food, poor oral hygiene, tissue abuse habits and trauma were identified as aggravating factors. Thirty nine $(36.1 \%)$ patients with OLP were found to have a tobacco, gutkha or betel nut chewing habit. Only five $(4.6 \%)$ patients were bidi or cigarette smokers. The duration of the habit ranged from 6 months to 10 years for most of the patients. Thirty-five patients claimed a history of stressful events, while 50 patients had poor oral hygiene at the time of diagnosis. Intraoral examination revealed that $41.7 \%$ of the patients presented with multiple oral lesions. The buccal mucosa was the site most affected (87.9\%), followed by the gingiva (29.6\%), tongue $(16.7 \%)$, lip mucosa $(14.8 \%)$ and vestibular fornix $(1.9 \%)$. The reticular form was observed in 87 (80.6\%) patients and the erosive form in 21 (19.4\%). A total of 74 patients reported symptoms, whereas 34 cases were asymptomatic. Among patients with asymptomatic lesions, 33 had reticular lesions while only had the erosive type. Oral discomfort and soreness was the most frequent symptom. Among patients with painful symptoms, $22.4 \%$ had the erosive form either alone or in association with the reticular form. Other signs and symptoms in descending order were gingival soreness and bleeding, mucosal roughness and pigmentation. Five 


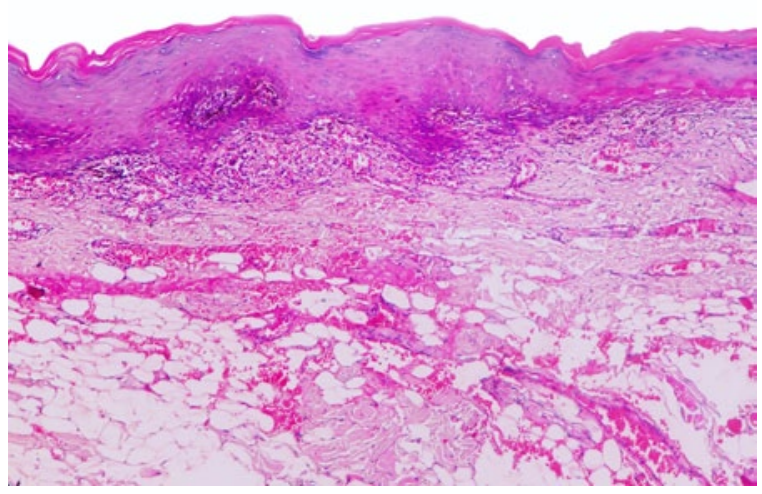

Fig. 1 Histological section showing epithelial hyperparakeratosis with marked lymphocytic infiltration immediately underlying the epithelium (HE staining, $\times 200$ magnification).

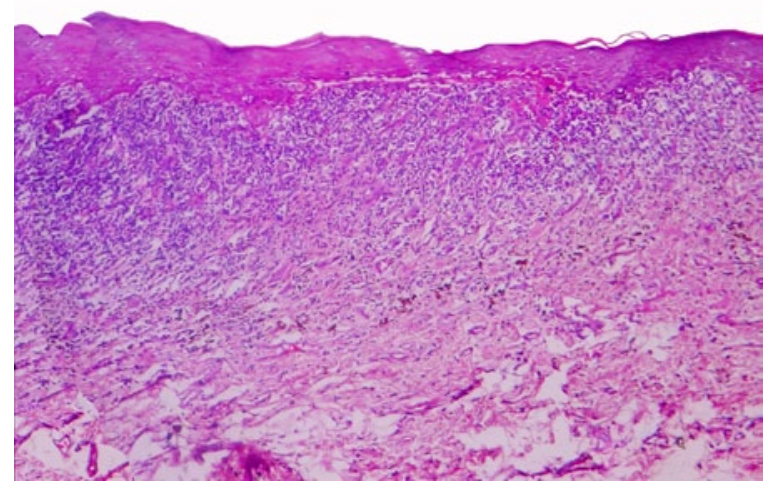

Fig. 3 Histological section showing areas of epithelial atrophy and a layered marked lymphocytic infiltrate in the lamina propria (HE staining, $\times 200$ magnification).

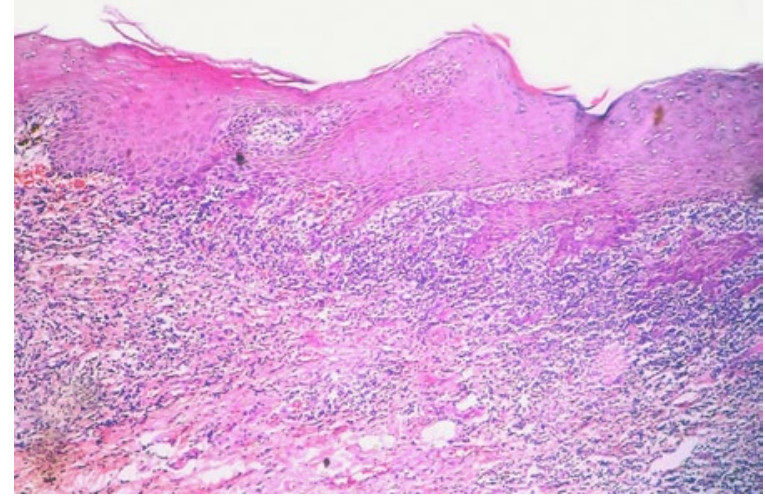

Fig. 2 Histological section showing mild acanthosis and basement layer lichenification with lymphocyte infiltration of the lamina propria (HE staining, $\times 200$ magnification).

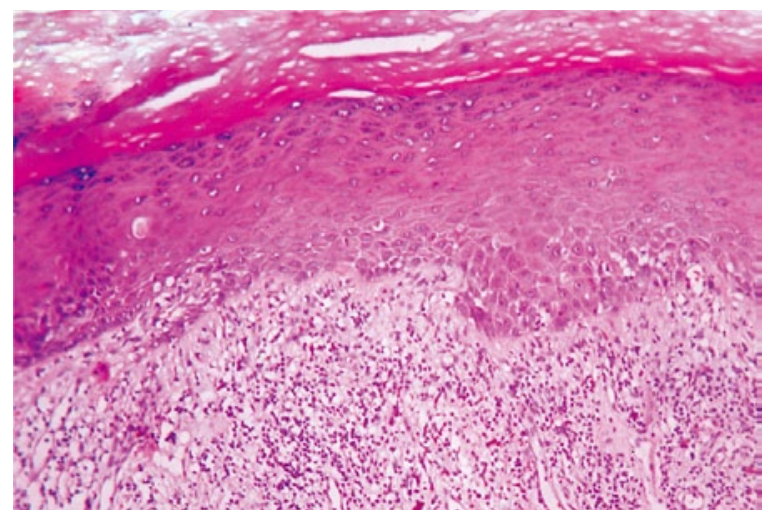

Fig. 4 Histological section showing hyperorthokeratosis with liquefaction degeneration of the basal cells in places (HE staining, $\times 400$ magnification).

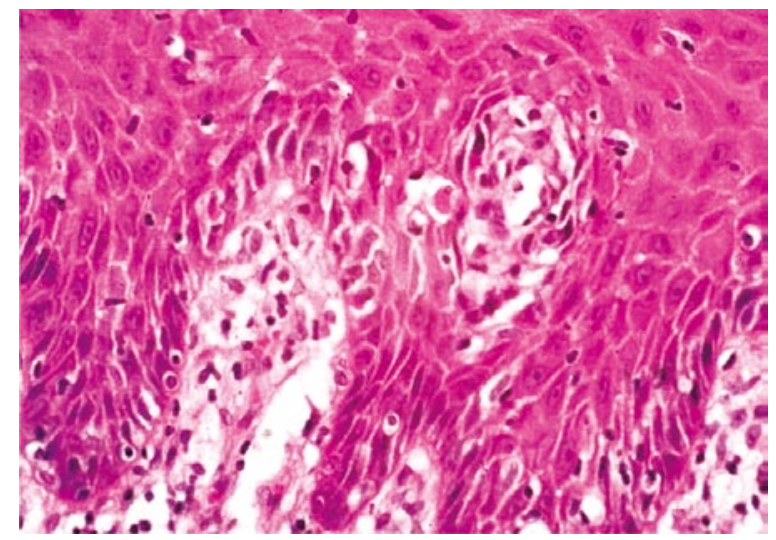

Fig. 5 Histological section showing basal layer liquefaction and civatte bodies in the center (HE staining, $\times 400$ magnification).

(4.6\%) patients had history of, or were diagnosed with extraoral lesions affecting the skin, nails and genitals. Accompaying systemic diseases included diabetes mellitus $(4.6 \%)$ and hypertension $(10.2 \%)$. None of the patients had a family history of OLP or malignant transformation. Among the 25 atypical lesions biopsied, only two showed dysplastic features histopathologically. The rest showed classic features of OLP such as liquefaction of the basal epithelial cells, lymphocyte infiltration of the lamina propria, normal maturation epithelium, a sawtooth appearance of the rete ridges, civatte bodies and hyperkeratosis (Figs. 1-5). Treatment was given in 


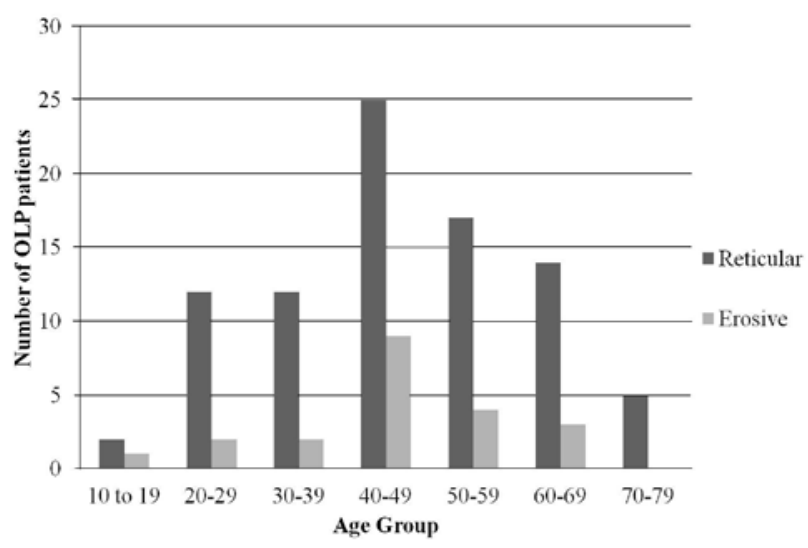

Fig. 6 Graph depicting age distribution of OLP patients according to subtype.

the form of topical steroids (as a mucosal adhesive paste or as intralesional injection) alone to $72(66.6 \%)$ patients and in combination with systemic steroids to two (1.8\%) patients with the goal of symptomatic relief. Patients receiving long-term maintenance therapy with topical steroids reported no local or systemic side effects except for oral candidiasis in three (2.8\%) cases. Lesion exacerbation was reported in $17(15.7 \%)$ cases.

\section{Discussion}

There are no universally accepted specific diagnostic criteria for OLP. OLP cases involving unilateral lesions clinically (34.3\%) and epithelial dysplasia histopathologically $(1.8 \%)$ in the present study would have been disqualified according to the van der Meij (13) system. However, they would have been classified as OLP according to the WHO system (14). Even van der Meij et al. (13) in their paper stated that application of these criteria would exclude a number of patients who may actually have the disease but do not meet the strict criteria. This discrepancy creates confusion when attempting to differentiate OLP from allied lesions, especially oral lichenoid lesions (OLL), and also creates a false record of malignant transformation if these excluded lesions undergo malignant transformation (15). Differentiation of OLP from OLL is important, as both are potentially malignant. Morever, van der Meij et al. showed that, among many cases, only OLLs turned malignant $(16,17)$.

Most of the literature has indicated that OLP occurs predominantly in adults aged over 40 years with a female predominance, and affects the buccal mucosa (18-21). In accord with this, predominance of OLP in the 5th decade with a female to male ratio of 2.3:1 was observed in the present study. The buccal mucosa was the site most affected, either alone or concomitantly with the gingivae. Isolated oral lesions were seen in $95.4 \%$ of the patients, and only $4.6 \%$ showed extraoral manifestations. This might have been due to the selective referral of patients to our department. The reticular form was the most frequent, followed by the erosive form, as has been documented by several investigators $(18,19,22,23)$. Figure 6 depicts the age distribution of OLP patients according to OLP subtype. The highest prevalence for both subtypes was found in the 40-49-year age group (31.5\%). When the incidence of these subtypes was compared by gender, male patients presented slightly earlier with OLP lesions than female patients. Oral discomfort and soreness was the most frequent symptom, being observed in $49.1 \%$ of cases; of these, $22.4 \%$ had the erosive form of OLP. The incidence of systemic diseases in the present study was lower than in other studies $(6,24,25)$. None of the literature data indicated an elevated prevalence of smoking or alcohol consumption among patients with OLP as compared with the general population, and this was also the case in the present study (26-29).

Confusing forms and patterns mimicking other diseases may pose difficulty in diagnosing otherwise clinically distinctive OLP patients with characteristic morphology and distribution. Most of the characteristic clinical findings in this series, such as predominance of the disease among middle-aged women, involvement of the buccal mucosa, presence of reticular lesions and pain, were similar to those reported previously. However our data underscore the need for more accurate and universally accepted diagnostic criteria than the existing ones, which can create confusion in diagnosing and differentiating true OLP cases from OLL cases.

\section{References}

1. Boorghani M, Gholizadeh N, Taghavi Zenouz A, Vatankhah M, Mehdipour M (2010) Oral lichen planus: clinical features, etiology, treatment and management; a review of literature. J Dent Res Dent Clin Dent Prospect 4, 3-9.

2. Scully C, Beyli M, Ferreiro MC, Ficarra G, Gill Y, Griffiths M et al. (1998) Update on oral lichen planus: etiopathogenesis and management. Crit Rev Oral Biol Med 9, 86-122.

3. Sugerman PB, Savage NW, Walsh LJ, Zhao ZZ, Zhou XJ, Khan A et al. (2002) The pathogenesis of oral lichen planus. Crit Rev Oral Biol Med 13, 350-365.

4. Payeras MR, Cherubini K, Fiqueiredo MA, Salum FG (2013) Oral lichen planus: focus on etiopathogenesis. Arch Oral Biol 58, 1057-1069.

5. Murti PR, Daftary DK, Bhonsle RB, Gupta PC, Mehta FS, Pindborg JJ (1986) Malignant potential of oral lichen planus: observations in 722 patients from India. J Oral Pathol 15, 
71-77.

6. Oliveira Alves MG, Almeida JD, Balducci I, Guimaraes Cabral LA (2010) Oral lichen planus: a retrospective study of 110 Brazilian patients. BMC Res Notes 3, 157.

7. Anuradha CH, Reddy BV, Nandan SR, Kumar SR (2008) Oral lichen planus. A review. N Y State Dent J 74, 66-68.

8. Eisen D (1999) The evaluation of cutaneous, genital, scalp, nail, esophageal, and ocular involvement in patients with oral lichen planus. Oral Surg Oral Med Oral Pathol Oral Radiol Endod 88, 431-436.

9. Sugerman PB, Savage NW (2002) Oral lichen planus: causes, diagnosis and management. Aust Dent J 47, 290-297.

10. Scully C, Carrozzo M (2008) Oral mucosal disease: lichen planus. Br J Oral Maxillofac Surg 46, 15-21.

11. van der Meij EH, Reibel J, Slootweg PJ, van der Wal JE, De Jong WF, van der Waal I (1999) Interobserver and intraobserver variability in the histologic assessment of oral lichen planus. J Oral Pathol Med 28, 274-277.

12. Gonzalez-Moles MA, Scully C, Gil-Montoya JA (2008) Oral lichen planus: controversies surrounding malignant transformation. Oral Dis 14, 229-243.

13. van der Meij EH, van der Waal I (2003) Lack of clinico-pathologic correlation in the diagnosis of oral lichen planus based on the presently available diagnostic criteria and suggestions for modifications. J Oral Pathol Med 32, 507-512.

14. Kramer IR, Lucas RB, Pindborg JJ, Sobin LH (1978) Definition of leukoplakia and related lesions: An aid to studies on oral precancer. Oral Surg Oral Med Oral Pathol 46, 518-539.

15. Patil S, Rao RS, Sanketh DS, Sarode SC, Sarode GS (2014) A universal diagnostic criteria for oral lichen planus: an exigency! Int J Contemp Dent Med Rev, 041214, 2014.

16. van der Meij EH, Schepman KP, van der Waal I (2003) The possible premalignant character of oral lichen planus and oral lichenoid lesions: a prospective study. Oral Surg Oral Med Oral Pathol Oral Radiol Endod 96, 164-171.

17. van der Meij EH, Mast H, van der Waal I (2007) The possible premalignant character of oral lichen planus and oral lichenoid lesions: a prospective five-year follow-up study of 192 patients. Oral Oncol 43, 742-748.
18. Xue JL, Fan MW, Wang SZ, Chen XM, Li Y, Wang L (2005) A clinical study of 674 patients with oral lichen planus in China. J Oral Pathol Med 34, 467-472.

19. Ingafou M, Leao JC, Porter SR, Scully C (2006) Oral lichen planus: a retrospective study of 690 British patients. Oral Dis 12, 463-468.

20. Pakfetrat A, Javadzadeh-Bolouri A, Basir-Shabestari S, Falaki F (2009) Oral lichen planus: a retrospective study of 420 Iranian patients. Med Oral Patol Oral Cir Bucal 14, e315318.

21. Gümrü B (2013) A retrospective study of 370 patients with oral lichen planus in Turkey. Med Oral Patol Oral Cir Bucal 18, e427-432.

22. Gorsky M, Raviv M, Moskona D, Laufer M, Bodner L (1996) Clinical characteristics and treatment of patients with oral lichen planus in Israel. Oral Surg Oral Med Oral Pathol Oral Radiol Endod 82, 644-649.

23. Hietanen J, Paasonen MR, Kuhlefelt M, Malmström M (1999) A retrospective study of oral lichen planus patients with concurrent or subsequent development of malignancy. Oral Oncol 35, 278-282.

24. Scully C, el-Kom M (1985) Lichen planus: review and update on pathogenesis. J Oral Pathol 14, 431-458.

25. Munde AD, Karle RR, Wankhede PK, Shaikh SS, Kulkurni M (2013) Demographic and clinical profile of oral lichen planus: a retrospective study. Contemp Clin Dent 4, 181-185.

26. Boyd AS, Neldner KH (1991) Lichen planus. J Am Acad Dermatol 25, 593-619.

27. Seoane J, Romero MA, Varela-Centelles P, Diz-Dios P, Garcia-Pola MJ (2004) Oral lichen planus: a clinical and morphometric study of oral lesions in relation to clinical presentation. Braz Dent J 15, 9-12.

28. Bajaj DR, Khoso NA, Devrajani BR, Matlani BL, Lohana P (2010) Oral lichen planus: a clinical study. J Coll Physicians Surg Pak 20, 154-157.

29. Al-Bayati S (2012) Oral lichen planus: a clinical study of 123 patients attending an oral medicine clinic, Baghdad University, Iraq. Gulf Med J 1, 10-14. 